\title{
時間的真理関数
}

\author{
杉原丈 夫
}

\section{Temporal truth-function}

\section{Takeo Sugihara}

All temporal truth-functions are expressed in the form of ordinary truth-function by the use of sequential variables.

The temporal truth-functions are classified in three categories: (1) Simple temporal truth-function, (2) Happening function and (3) Sequential function.

Some fundamental temporal truth-functions are as follows: Afterhappening function, $H p$. (After the happening of $p$ ) Delay function, $D p$. (Delaying $p$ for an interval) Jumping function, $J p$. (Jumping over a positive interval of $p$ ) Temporal conjunction, $K(p, q)$. ( $p$ and $q$, but $p$ before q.)

$$
\begin{aligned}
& H p \equiv s \\
& D p \equiv \sim p \wedge H p \\
& J p \equiv p \wedge \sim s_{1} \\
& K(p, q) \equiv(p \wedge q) \wedge s(p)
\end{aligned}
$$

まえがき これまでの論理学は「として」「または」「もしならば」など超時間 的論理関係のみを研究の対象としていた。本稿は「前」「後」「間」などの時間的 関係を論理学に導入し，真理関数で表現することを目的とする。

本稿は先に発表した「序列真理関数——時間を含む論理学 (第 1 報)」科学哲学 年報第 2 巻（1962） の続報である。しかし前報の単なる続編でなく, 全く別の着 想から根本的に改稿して，前報で未解決であった一般問題に簡明な解決を与兄 た。 


\section{§1. 時間的真理関数}

時間的命題 たと衤ば「この部屋は 10 人の人がいる。といら命題を $p$ で表わ せば，この部屋に人が出入りしているので，pの真偽は時間によって変化する。 命題の真偽が時間の関数であるとき，これを時間的命題という。「2+2=4」のご とくその真偽が時間任関係ない命題も，それはすべての時間に扔いて真であると 考光れば，やはり時間的命題である。

相互に独立な $n$ 個の時間的命題 $p_{1}, p_{2}, \cdots \cdots, p_{n}$ を基項（アーギュメント）とす る命題関数 $\Phi\left(p_{1}, p_{2}, \cdots \cdots, p_{n}\right)$ の真偽が，基項の真偽によっての反定まるとき， この関数を時間的真理関数という。時間的真理関数は，次のように分類できる。

1. 絶対的時間的真理関数 $\Phi\left(p_{1}, p_{2}, \cdots \cdots, p_{n}\right)$ の各時刻飞特ける值が, 基項 $p_{1}, p_{2}, \cdots \cdots, p_{n}$ のその時刻飞扝忊る值の真理関数として単純住定るるの。この 場合関数 $\Phi$ は通常の真理関数として表現でさるから，新たな関数を導入する必要 がない。

2. 相対的時間的真理関数

(a) 生起関数 $\Phi(p)$ の值が，その時刻に括けるpの值だけでなく， なる時刻，すなわち $p か ゙$ 生起する時刻との相対的前後関係化よって定まるとき， この関数を生起関数という。

(b) 序列関数 $\Phi\left(p_{1}, p_{2}, \cdots \cdots, p_{n}\right)$ の值吕，先の時刻飞括ける $p_{1}, p_{2}, \cdots \cdots, p_{n}$ の值だけではなく，それに先立つ時刻に括ける $p_{1}, p_{2}, \cdots \cdots, p_{n}$ の值によって定ま るとき,この関数を序列関数という。

区 間 時間は連続であるが，通常の命題では，時間の単位を十分小さくとれ ば，時間が単位時間ごとに不連続に進むと考学ても，実際上さてつか觉ない。

相互に独立な $n$ 個の時間的命題 $p_{1}, p_{2}, \cdots \cdots, p_{n}$ の集合Mを考兄る。ある単位時 間に和けるこれらの $n$ 個の命題の值の可能な組合せは $2^{n}$ 通りある。この組合せ をるって集合Mの值とする。隣接した単位時間飞おいて集合Mの値が同でである とき，それらの単位時間を併合して一つの区間とする。かくすればMの值は区間 ごとに変化し，区間の関数となる。 
な特Mの值は 1 区間につき一つの命題のみが値を変化する。二つ以上の命題が 同時に值を変化することはないものとする。現実に同時に変化したように見える 場合でも，時間の単位を十分小さくして，前後の差をつけることにする。

また，特に必要がない限り，時間の始点において， $p_{1}, p_{2}, \cdots \cdots, p_{n}$ の值はすべ て為，すなわち0であるとする。時間的命題 $p$ の值が真である区間を $p$ の正区 間， $p$ の值が偽である区間を $p$ の負区間という。

\section{$\S 2$. 生 起 関 数}

生起後関数 たと放ば「キリストが生存している。という命題を $p$ で表わす とき，全時間は $p$ にりキリスト出生前，生存中，死後の 3 区間に区分される。 いま「キリスト出生前である。を $B p$ で,「キリスト出生後である。」を $H p$ で 表わし， 3 区間と $p, B p, H p$ の関係を表示すると次のようになる。

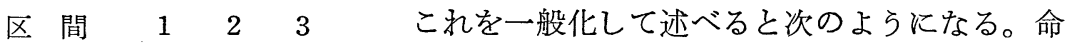
$p \quad 0 \quad 1 \quad 0 \quad$ 題 $p$ で表現される事象が全時間中に $k$ 回起るるの

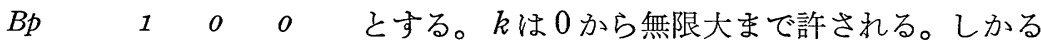
$H p \quad 0 \quad 1 \quad 1 \quad$ とさは全時間は $p$ により $2 k+1$ 区間に区分され る。ただしこれは時間の始点と終点において $p$ が生起しない場合である。始点と 終点に特いて $p$ が生起している場合は $2 k-1$ 区間であり，その他の場合は $2 k$ 区 間になる。

区間が $m$ のとき，可能な関数の種類は $2^{m}$ 通りある。Bp と $H p$ はそのうちの 2 種である。しかしこれらの関数は通常の真理関数で表現できない。なぜなら ば, 単項真理関数は $p, \sim p, t$ (恒真真理関数), $f$ (恒偽真理関数) の 4 種しかな く, 残りの $2^{m}-4$ は通常の真理関数では表現不可能である。

一般の場合，Hp 和よび $B p$ は次のように定義される。 すなおち $v(p)=1$ を，簡略のため $p=1$ で表わす。 $p=0$ も同様である。 $H p$ は $p$ の最初の生起以後は常に $p=1$ であり, 生起の前は $p=0$ である。反対に $B p$ は $p$ の最初の生起以後は常に $p=0$ であり, 生起の前は $p=1$ である。故に

$$
B p \equiv \sim H p
$$


よって今後は $H p$ だけについて考兄る。 $H p$ を生起後関数， $B p$ を生起前関数と いらことにする。

$H p$ を真理関数で表わすために補助的な変項 $s$ を加え，この $s$ を序列変項とい う。 $s$ は次の性質を有する。

(i) $s$ は pの従属変項であって, 次の式で規定される。

$$
s \equiv p \vee s
$$

(ii) $s$ は，両様の值が可能なとき，前の区間に怙ける值を保守する。

(iii) $s$ は，第 1 区間飞和いて両様の值が可能なとさ， $s=0$ である。

(i)により $p$ と の值の組合せは $11,01,00$ であって，p=1,s=0 といら 組合せは生じない。また(ii)により 1 度 $s=1$ 亿なれば，あとはずっと $s=1$ であ る。その関保を表示すると次のようになる。

$\begin{array}{ccccccccc}\text { 区 間 } & 1 & 2 & 3 & 4 & 5 & 6 & 7 & \ldots \ldots \ldots . \\ p & 0 & 1 & 0 & 1 & 0 & 1 & 0 & \ldots \ldots \ldots . . \\ s & 0 & 1 & 1 & 1 & 1 & 1 & 1 & \ldots \ldots . . . \\ H p & 0 & 1 & 1 & 1 & 1 & 1 & 1 & \ldots \ldots . . .\end{array}$

上表からただちに次の式を得る。

$$
H p \equiv s
$$

遅延関数 $\quad p$ の值より 1 区間ずつ遅れて $p$ と同じ値をとる関数を遅延関数とい い, $D p$ で表わす。 $D p$ よりるさらに 1 区遅延した関数，すなわち $D D p を D p^{2}$ で表わす。 $D p^{2}$ は $p$ の值より 2 区間遅延している。その関係を表示すると次のと おりである。

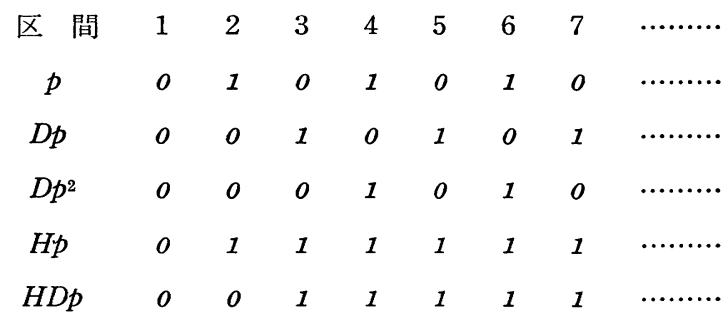

上表から次の式を得る,

$$
D p \equiv \sim p \wedge H p
$$




$$
D^{2} p \equiv p \wedge H D p
$$

これを一般化すれば

$$
\begin{aligned}
& D^{2 m} p \equiv p \wedge H D^{2 m-1} p \\
& D^{2 m+1} p \equiv \sim p \wedge H D^{2 m} p
\end{aligned}
$$

逆方向にも延長解积して

$$
\begin{aligned}
& D^{0} p \equiv p \\
& D^{-1} p \equiv \sim p
\end{aligned}
$$

ただし $(2 \cdot 9)$ は第 1 区間に执いて $p=0$ の場合に限る。

跳躍関数 $p$ の正区間を一つ飛びに自分の正区間とする関数を跳躍 関数とい

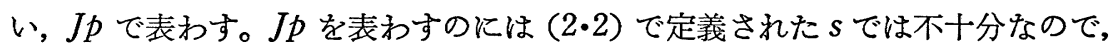
新たに二つの序列率項 $s_{1}$ ，および $s_{2}$ を用いる。 $s_{1}$ と $s_{2}$ の值の組合せを $s_{1} s_{2}$ で 表わせば， $s_{1} s_{2}$ は $00,01,11,10$ の順で循環する。 $s_{1}$ と $s_{2}$ はいずれか一方 が一つずつ変化し，二つが同時に変化することはないるのとする。

$\begin{array}{cccccccccc}\text { 区 間 } & 1 & 2 & 3 & 4 & 5 & 6 & 7 & 8 & \ldots \ldots \ldots \\ p & 0 & 1 & 0 & 1 & 0 & 1 & 0 & 1 & \ldots \ldots \ldots \\ J p & 0 & 1 & 0 & 0 & 0 & 1 & 0 & 0 & \ldots \ldots \ldots \\ s_{1} & 0 & 0 & 1 & 1 & 0 & 0 & 1 & 1 & \ldots \ldots \ldots \\ s_{2} & 0 & 1 & 1 & 0 & 0 & 1 & 1 & 0 & \ldots \ldots \ldots\end{array}$

$s_{1}$ および $s_{2}$ は次の性質を有する。

(i) $s_{1}$ 括よび $s_{2}$ は $p$ の従属変項であって, 次の式で規定される。

$$
\begin{aligned}
& s_{1} \equiv\left(p \wedge s_{1}\right) \vee\left(\sim p \wedge s_{2}\right) \\
& s_{2} \equiv\left(p \wedge \sim s_{1}\right) \vee\left(\sim p \wedge s_{2}\right)
\end{aligned}
$$

(ii) $s_{1}$ 特よび $s_{2}$ は，両様の值が可能なとき，前の区間に打ける值を保守す る。

(iii) $s_{1}$ 特よび $s_{2}$ は，第 1 区間に特いて両種の值が可能なとき， $s_{1}=0$ 拈よび $s_{2}=0$ である。

$(2 \cdot 10)$ の式は次のようにして得られた。 $s_{1}=1$ であるのは, 循環する区間（第 1 から第 4 まで）のらち第 3 と第 4 の区間である。第 3 区間では， $s_{1}$ は前区間か 
ら值が変動し， $s_{2}$ は変動しない。変動しない $s_{2}$ の方をとり， $s_{1} \equiv\left(\sim p \wedge s_{2}\right)$ で ある。第 4 区間では， $s_{1}$ は前区間から值が変動せず， $s_{2}$ は変動している。故に 変動しない $s_{1}$ の方をとり， $s_{1} \equiv\left(p \wedge s_{1}\right)$ である。この両者を合せれば，(2・10） の第 1 式となる。第 2 式㴟いても同様である。

しかるときは $J p$ は次の式となる。

$$
J p \equiv p \wedge \sim s_{1}
$$

$J p=1$ となるのは循環する区間のうち第 2 区間である。第 2 区間で $s_{2}$ は前区 間から值が変動するが， $s_{1}$ は変動しない。故に変動しない方の $s_{1}$ をとって（2・ 11）が得られる。

一般的な跳躍関数 $J_{k} p$ を次のように定義する。 $p$ の正区間を $k$ 番目ごとにと ったものを $J_{k} p$ の正区間とする。従って $J_{k} p$ は $2 k$ 区間ごとに関数の值が循環 する。 $J_{k} p$ を真理関数で表現するために $m$ 個の序列変項を用いる。 $m$ の值は次の 式で与兄らる。

$$
2^{m-1}<2 k \leq 2^{m}
$$

しかるときは $J_{k} p$ は次の式となる。

$$
J_{k} p \equiv p \wedge \sim s_{1} \wedge \sim s_{2} \wedge \cdots \cdots \cdots \wedge \sim s_{m-1}
$$

しかし $s_{1}, s_{2}, \cdots \cdots, s_{m}$ を規定する式は， $m$ の值が同じでも， $k$ の值によって異 なる。 $k=3$ 执よび $k=4$ によって例示すれば，いずれの場合も $m=3$ であるか ら,

$$
\begin{aligned}
& J_{3} p \equiv p \wedge \sim s_{1} \wedge \sim s_{2} \\
& J_{4} p \equiv p \wedge \sim s_{1} \wedge \sim s_{2}
\end{aligned}
$$

両式は全く同じである。しかし $s_{1}, s_{2}, s_{3}$ が異なる。

一般に $m$ 個の序列変項の值の組合せは，次の順序で配列される。最初は全部が 0 である。次にまず $s_{m}=1$ となる。その次に $s_{m-1}=1$ となる。次に $s_{m}$ はもど り， $s_{m}=0$ となる。こんどは $s_{m-2}$ に移り， $s_{m-2}=1$ となる。ついで先と同じ ように $s_{m}, s_{m-1}, s_{m}$ という順序で変化して, $s_{m-3}$ に移る。以下この手順を絽り返 す。要するに $m$ 個の変項は一つずつ值を変えて行き, 二つ以上が同時に值を変兄 ることはない。 $m=3$ で例示すれば次のと括りである。 


$$
\left[\begin{array}{l}
000 \rightarrow 001 \rightarrow 011 \rightarrow 010 \\
100 \leftarrow 101 \leftarrow 111 \leftarrow 110 \leftarrow
\end{array}\right]
$$

$k=4$ のときは， $2 k=8$ であるから，この 8 組の值をすべて用いればよい。し かし $k=3$ のときは， $2 k=6$ であるから， 2 組だけ余る。故に 2 組を除去し，残 りの 6 組が，変項の值を一つずつ変化させて接続するようにすればよい。具体的 飞は(001，011)を除いてもよく，(010，110)を除いてもよく，(111，101) を除いてもよい。しかし $(2 \cdot 14) ，(2 \cdot 15)$ が成立するためには（001，011）は 除かれない。いま $(111,101)$ を除くと，次の表になる。

$\begin{array}{cccccccc}\text { 区 間 } & 1 & 2 & 3 & 4 & 5 & 6 & \ldots \ldots \ldots . \\ s_{1} & 0 & 0 & 0 & 0 & 1 & 1 & \ldots \ldots . . . \\ s_{2} & 0 & 0 & 1 & 1 & 1 & 0 & \ldots \ldots \ldots . \\ s_{3} & 0 & 1 & 1 & 0 & 0 & 0 & \ldots \ldots \ldots . \\ p & 0 & 1 & 0 & 1 & 0 & 1 & \ldots \ldots \ldots . \\ J_{3} p & 0 & 1 & 0 & 0 & 0 & 0 & \ldots \ldots \ldots . .\end{array}$

この表から $s_{1}, s_{2}, s_{3}$ を規定する式を得る。

$$
\begin{aligned}
& s_{1} \equiv\left(\sim p \wedge s_{2} \wedge \sim s_{3}\right) \vee\left(p \wedge s_{1} \wedge \sim s_{3}\right) \\
& s_{2} \equiv\left(\sim p \wedge \sim s_{1} \wedge s_{3}\right) \vee\left(p \wedge \sim s_{1} \wedge \sim s_{2}\right) \vee\left(\sim p \wedge s_{2} \wedge \sim s_{3}\right) \\
& s_{3} \equiv\left(p \wedge \sim s_{1} \wedge \sim s_{2}\right) \vee\left(\sim p \wedge \sim s_{1} \wedge s_{3}\right)
\end{aligned}
$$

$k=4$ の場合は省略するが，(2・16）と異なる式になることはいうまでもない。

\section{§3. 生起関数の還元}

定 理 1 有限区間のすべての生起関数は, 真理関数と $H p$ に還元できる。

証明 区間の番号付けは， $p$ の最初の正区間を第 1 区間とする。従って時間の 始点に和いて $p=0$ であるとき，第 1 区間の前に第 0 区間を置く。いま第 $i$ 区間 そ拈いてのみその值が 1 となり，他の区間では 0 である関数を $T_{i} p$ で表わす。 しかるときは， $i=0$ の場合

$$
T_{o} p \equiv \sim H p
$$

$i \neq 0$ の場合 


$$
T_{i} p \equiv D^{i-1} p \wedge \sim H D^{i} p
$$

あるいは次のようにも表現できる。

$$
T_{i} p \equiv D^{i-1} p \wedge \sim D^{i+1} p
$$

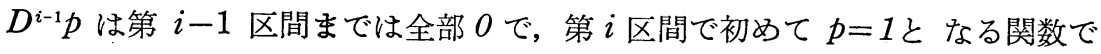
ある。これに対し HD ${ }^{i} p$ は第 $i+1$ 区間以後すべて 0 である関数， $\sim D^{i+1} p$ は 第 $i+1$ 区間以後正負が $D^{i-1} p$ と反対になっている関数である。故にそれと $D^{i-1} p$ との連言は，第 $i$ 区間のみ 1 となり，他の区間は 0 となる。

いま任意の生起関数 $\Phi p$ は, 第 $a$, 第 $b$, 第 $c \cdots \cdots$ 区間でその值が 1 で, 他の 区間では 0 であるとする。しかるときは $\Phi p$ は次のごとく表現できる。

$$
\Phi p \equiv T_{a} p \vee T_{b} p \vee T_{c} p \vee \cdots \cdots \cdots
$$

かくて $\Phi p$ は $T_{i} p$ に還元され， $T_{i} p$ は $D^{m} p$ に還元され， $D^{m} p$ は (2.4) ないし (2・7) で示したごとく $H p$ に還元される。

定 理 2 循環無限区間の生起関数は $H p$ と $J_{k} p$ に還元でさる。

証明 生起関数 $\Phi p$ は, 最初第 $2 h$ 区間までは非循環部分, 第 $2 h+1$ 区間以 後は $2 k$ 区間ごとの循環部分であるとする。この $2 h$ は, $p$ の最初の正区間を第 1 区間として数えた区間番号である。もし非循環部分の区間番号が奇数で終ると きは，循環部分の最初の 1 区間を非循環部分に加光，次の区間から循環が始まる ものとする。たと兊ば,

$$
O[01][01] \cdots \cdots . . . .
$$

であるときは

$$
00[10][10] \cdots \cdots \cdots
$$

とする。

関数 $\Phi_{0} p$ は，最初の第 $2 h$ 区間をでは $\Phi p$ の非循環部分と同じ值であり，第 $2 h+1$ 区間以後は全部 $O$ である関数とする。また $\Phi_{1} p$ は，最初の第 $2 h$ 区間ま では全部 $O$ で, 第 $2 h+1$ 区間以後は $\Phi p$ の循環部分と同じ值であるとする。乙 かるときは

$$
\Phi p \equiv \Phi_{0} p \vee \Phi_{1} p
$$

$\Phi_{0} p$ の正区間は最初の第 $2 h$ 区間までにしかない。それを第 $a$ ，第 $b$ ，第 $c$ 
・間とする。しかるときは

$$
\Phi_{0} p \equiv T_{a} p \vee T_{b} p \vee T_{c} p \vee \cdots \cdots \cdots
$$

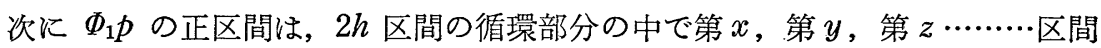
$(2 k$ 区間の中の最初の区間を第 1 区間と数えて）であるとする。しかるとさは第 $x$ 区間は，全体から見れば第 $2 h+x$ 区間である。故に

$$
\Phi_{1} p \equiv J_{k} D^{2 n}\left(D^{x-1} p \vee D^{y-1} p \vee D^{z-1} p \vee \cdots \cdots \cdots\right)
$$

\section{§4. 序 列 関 数}

2 区間序列関数 簡単な例から述べる。「受話器をはずす。」を $p$ ，「ダイヤル を回す。」 $q て ゙$ 表わす。しかるときは，同じ $p \wedge q$ でも， $p$ が先であるのと $q$ が先であるのとでは結果が異なる。 $p$ と $q$ が共に真で，しかもpが先に真とな り，qが後に真となったとき，かつそのときにのみ関数の值が真となる関数を $K(p, q)$ で表わし，「pが $q$ より先」と読むことにする。 $K(p, q)$ を時間連言と いう。この関係を表示すると次のようになる。現在の区間は第 $i$ 区間であると し，その前の区間すなわち第 $i-1$ 区間に和梳る $p$ および $q$ の值が $K(p, q)$ の 值を左右する。

区 間

$$
i-1
$$

$i$

$\begin{array}{ccccc}p & q & p & q & K(p, q) \\ 1 & 0 & 1 & 1 & 1 \\ 0 & 1 & 1 & 1 & 0\end{array}$

第 $i$ 区間において $p \wedge q$ の值が 1 でないときは，もちろん $K(p, q)$ の值は $O$ である。

$K(p, q)$ を真理関数で表わすため二つの序列変項 $s(p)$ と $s(q)$ を用いる。第 $t$ 区間に叔ける $p, q$ の值を $p(t), q(t)$ で表わせば， $s(p)$ は $p(i-1)$ と $p(i)$ の值が同じときにのみ 1 となり，他のときは 0 である。同様に $s(q)$ は $q(i-1)$ と $q(i)$ が同じで值のときにのみ 1 となる。すなおち

$$
\begin{aligned}
& s(p) \equiv(p(i-1) \equiv p(i)) \\
& s(q) \equiv(q(i-1) \equiv q(i))
\end{aligned}
$$


$p$ と $q$ は同時に值が変化することなく, 各区間でどちらかが一つずつ值を変え るものとすれば,

$$
s(p) \equiv \sim s(q)
$$

故に理論的には二つの序列変項のらち一つだけがあればよい。この序列変項を 使えば, $K(p, q)$ は次の式で与えられる。

$$
K(p, q) \equiv(p \wedge q) \wedge s(p)
$$

$q$ が先に真で, $p$ が後に真である時間連言は次の式となる。

$$
K(q, p) \equiv(q \wedge p) \wedge s(q)
$$

これを一般化して，2 区間序列関数 $\Phi(p, q)$ を次のょうに定義する。 $\Phi(p, q)$ は二つの時間的命題 $p$ \& $q$ を基項とし, 関数の值は, 現在の第 $i$ 区間に括ける $p$ と $q$ の真理值だけでなく, それに先立つ第 $i-1$ 区間に和ける $p$ と $q$ 真理值に よって決定される。

定 理 3 任意の 2 区間序列関数 $\Phi(p, q)$ は $K(p, q)$ に還元できる。

証明 第 $i-1$ 区間叔よび第 $i$ 区間に括ける $p$ 抢よび $q$ の值の組合せは次の表 示すごとく 8 通りある。次の 8 通りの時間連言は, $p$ 和よび $q$ の 8 通りの值の 組合せに対し, それぞれ 8 行のうち 1 行だけに拈いて 1 の值をとり, 他の行では ○の值をとる関数である。

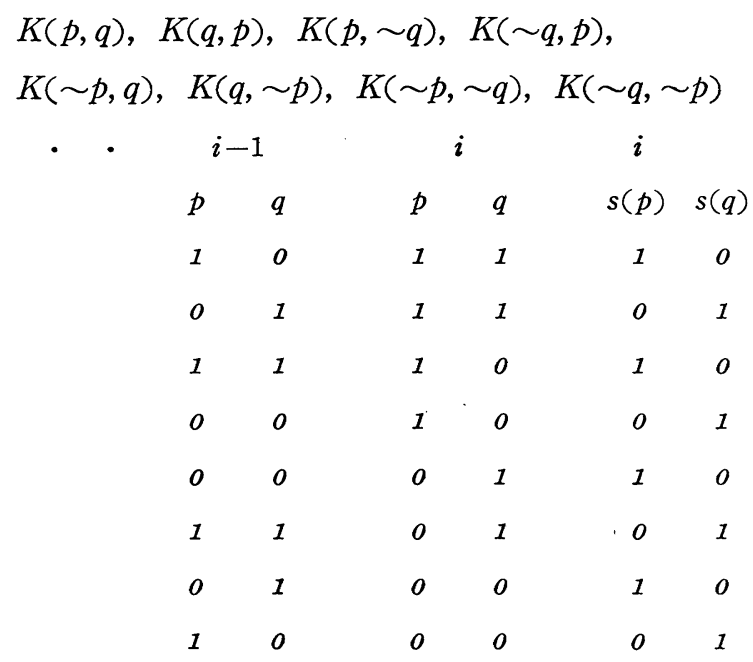


この 8 通りの時間連言を仮に原子序列関数といい，それぞれ $A_{1}, A_{2}, \cdots \cdots, A_{8}$ で表わす。しかるときは任意の 2 区間序列関教 $\Phi(p, q)$ は，るし上表の 8 行のう ち第 $a$ 行と第 $b$ 行等において 1 であり, 他の行で 0 であるとさは,

$$
\Phi(p, q) \equiv A_{a} \vee A_{b} \vee \cdots \cdots \cdots
$$

定 理 4 任意の $n$ 項 2 区間序列関数 $\Phi\left(p_{1}, p_{2}, \cdots \cdots, p_{n}\right)$ は $K(p, q)$ に還元 できる。

証明 一般に関教 $\Phi\left(p_{1}, p_{2}, \cdots \cdots, p_{n}\right)$ の值が第 $i$ 区間および第 $i-1$ 区間に括 将る $p_{1}, p_{2}, \cdots \cdots, p_{n}$ の值によって定まるとき，この関数を $n$ 項 2 区間序列関数と いう。第 $i$ 区間に拉ける $p_{1}, p_{2}, \cdots \cdots, p_{n}$ の值の組合は $2^{n}$ 通りある。それに対し 第 $i-1$ 区間に叔ける $p_{1}, p_{2}, \cdots \cdots, p_{n}$ の值はとれぞれ $n$ 通りである。なぜならば, 各区間に括いて変項の值は一つだけ変化し，二つ以上が同時に変化することはな いものとして約束してあるからである。しかるときは両区間に和ける基項の值の 組合せは $n \times 2^{n}$ である。

これに対し $n$ 項時間連言 $K\left(p_{1}, p_{2}, \cdots \cdots, p_{n}\right)$ を次のように定義する。第 $i$ 区間 飞怙いて $p_{1}, p_{2}, \cdots \cdots, p_{n}$ のすべての值が 1 であり，かつ第 $i-1$ 区間で $p_{n}$ のみ が 0 , 他はすべて 1 であるとき，かつそのときにのみ， $K\left(p_{1}, p_{2}, \cdots \cdots, p_{n}\right)$ の值 は 1 である。しかるときは $n$ 項時間連言は 2 項時間連言に還元される。

$$
K\left(p_{1}, p_{2}, \cdots \cdots, p_{n}\right) \equiv K\left(\left(p_{1} \wedge p_{2} \wedge \cdots \cdots \wedge p_{n-1}\right), p_{n}\right)
$$

この $n$ 項時間連言をもとにして, $n \times 2^{n}$ 通りの $n$ 項原子序列関数を作りらる。 しかるときは定理 3 と同様にして, 任意の $n$ 項 2 区間序列関数は原子序列関数の 選言で表現でさる。

$(\mathbf{t}+\mathbf{1})$ 区間序列関数 関数 $\Phi\left(p_{1}, p_{2}, \cdots \cdots, p_{n}\right)$ の值が，第 $i-t$ 区間から第 $i$ 区間までの $t+1$ 区間に和ける $p_{1}, p_{2}, \cdots \cdots, p_{n}$ の值によって定まるとき，この関 数を $(t+1)$ 区間序列関数という。

$(t+1)$ 区間序列関数を真理関数で表現するために，各 $p_{j}(j=1, \cdots \cdots, n)$ につ き $t$ 個ずつ，みなで $n t$ 個の序列変項を用いる。

$$
\begin{aligned}
& s_{x}\left(p_{j}\right) \equiv\left(p_{j}(i-x-1) \equiv p_{j}(i-x)\right) \\
& s_{x}\left(p_{j}\right) \equiv \prod_{1 \leqslant k \leqslant n} \sim s_{x}\left(p_{k}\right) \quad(j \neq k)
\end{aligned}
$$


ただし $\Pi$ は各項を連言で結合することを意味し， $x$ は 1 から $t$ までの任意の数， $j$ は 1 から $n$ までの任意の数とする。 $i$ が小さくて $i \leq x+1$ の場合は, $s_{x}\left(p_{j}\right)$ は欠除しているものとする。そのときは関数の值自体も欠除している。すなわち $i \leq t$ のときは，関数の值はない。

簡単な例をあげる。最初第 $i-2$ 区間で $p=0, q=0$ であって, 次に第 $i-1$ 区間で $p=1$ となり，さらに第 $i$ 区間で $q=1$ となったとさ，かつそのときに のみ, 関数の值が 1 .であるような関数を $K_{01}(p, q)$ で表わす。01 といら下付字 は, 第 $i-2$, 第 $i=1$ 区間に拈ける $p$ の值である。この関係を表示すれば, 次の と特りである。

区 間 $i-2 \quad i-1 \quad i$

乗 項 $\quad p \quad q \quad P \quad p \quad q \quad p \quad p \quad q \quad s_{1}(p) s_{1}(q) s_{2}(p) s_{2}(q) K_{01}(p, q)$

$\begin{array}{lllllllllll}0 & 0 & 1 & 0 & 1 & 1 & 1 & 0 & 0 & 1 & 1 \\ 1 & 1 & 1 & 0 & 1 & 1 & 1 & 0 & 1 & 0 & 0 \\ 0 & 0 & 0 & 1 & 1 & 1 & 0 & 1 & 1 & 0 & 0 \\ 1 & 1 & 0 & 1 & 1 & 1 & 0 & 1 & 0 & 1 & 0\end{array}$

（下 略）

従って

$$
K_{01}(p, q) \equiv(p \wedge q) \wedge s_{1}(p) \wedge s_{2}(q)
$$

最終学歴：

昭和15年 京都大学文学部哲学科卒業

主な著者：

「様相論理学」山喜房

「数学的論理学」槙畫店 